\title{
Comparison of Two Arthroscopic Coracoplasty Approaches in Subscapularis Tears
}

\author{
Han-Eui Song, Suk-Hwan Jang ${ }^{\square}$, Jung-Gon Kim \\ Department of Orthopedic Surgery, Inje University Seoul Paik Hospital, Seoul, Korea
}

\begin{abstract}
Background: Few studies have reported the results of arthroscopic coracoplasty concomitantly conducted with subscapularis tear. Therefore, this study was conducted to examine and compare the outcomes of arthroscopic subscapularis repair after arthroscopic coracoplasty using either the subacromial approach or rotator interval approach.

Methods: We retrospectively reviewed 51 patients who underwent coracoplasty with subscapularis repair. The patients were grouped according to whether the subacromial approach group (24 patients) or rotator interval approach group (27 patients) was used during coracoplasty. Preoperative and postoperative visual analogue scale scores, American shoulder and elbow surgeons scores, Korean shoulder scores, and range of motion (ROM) were assessed. Assessment of repaired rotator cuff tendon integrity was performed at 1 year after surgery using either magnetic resonance imaging or ultrasonography.

Results: At final follow-up, overall functional scores and ROM improved significantly in both groups when compared with preoperative values $(p>0.05)$. The re-tear rates were not significantly different between groups; however, the rotator interval approach group showed a significant increase in ROM compared with that in the subacromial approach group $(p<0.05)$.

Conclusions: Arthroscopic coracoplasty conducted concomitantly with subscapularis repair can provide a satisfactory outcome. There were no significant differences between the two approach groups regarding final functional scores and re-tear rates. However, the rotator interval approach group showed a greater increase in ROM at final follow-up, especially in external rotation.
\end{abstract}

(Clin Shoulder Elbow 2017;20(4):189-194)

Key Words: Shoulder; Rotator cuff tears; Subscapularis; Arthroscopy; Coracoplasty

\section{Introduction}

The associations between narrow coracohumeral distance (CHD) and subscapularis tears have been proposed by various authors. $^{1-5)}$ Lo and Burkhart ${ }^{6)}$ reported concomitant coracoplasty would be necessary in the subscapularis repair to widen the stenotic subcoracoid space and reduce the retear rate of the repaired subscapularis tendon. Moreover, several reports have shown that either arthroscopic or open coracoplasty yields satisfactory outcomes. ${ }^{3,7,8)}$ Because of the established correlation, some authors even suggested performing arthroscopic coracoplasty concomitantly with subscapularis repair, even without evident narrow CHD. ${ }^{2)}$ Although the most common reported surgical treatment for decompressing the subcoracoid space is open anterior approach, arthroscopic coracoplasty has gained popularity, along with arthroscopic subscapularis repair. Karnaugh et al. ${ }^{1)}$ first reported a technique of arthroscopic coracoplasty through a subacromial (SA) approach. Lo and Burkhart ${ }^{2}$ reported arthroscopic coracoplasty through the rotator interval (RI) approach. Since introduction of coracoplasty through the $\mathrm{RI}$ approach, this procedure has been commonly performed. However, no studies have reported comparative results after the two procedures to date. Therefore, the current study was conducted to revalidate the usefulness of arthroscopic coracoplasty in subscapularis tears and compare the clinical outcomes and re-tear rates of repaired rotator cuffs, including the subscapularis

Received July 12, 2017. Revised September 17, 2017. Accepted September 22, 2017.

Correspondence to: Suk-Hwan Jang

Department of Orthopedic Surgery, Inje University Seoul Paik Hospital, 9 Mareunnae-ro, Jung-gu, Seoul 04551, Korea

Tel: +82-2-2270-0028, Fax: +82-2-2270-0023, E-mail: orthopodjang@gmail.com

IRB approval (No. PAIK 2016-12-004).

Financial support: None. Conflict of interests: None. 
tendon, of two different approaches.

\section{Methods}

We retrospectively reviewed prospectively collected data of patients who underwent arthroscopic subscapularis repair with concomitant coracoplasty by the SA approach between July 2011 to December 2012 and those who underwent arthroscopic coracoplasty with a RI approach from January 2013 to July 2014. A single surgeon performed all operations. The protocol of this study was approved by Institutional Review Board of Inje University Seoul Paik Hospital (IRB No. PAIK 2016-12-004).

Patients were included in this study if they had undergone arthroscopic subscapularis repair with coracoplasty and were available for follow-up for a minimum of 12 months with ultrasonographic evaluation or magnetic resonance imaging (MRI). The exclusion criteria were patients who had coracoplasty without subscapularis repair, massive rotator cuff tears involving both supraspinatus and infraspinatus, complete subscapularis tear of more than type 4 according to Lafosse et al., ${ }^{9}$ severe stiffness of the shoulder with less than $100^{\circ}$ of forward elevation, and revision surgeries. A total of 51 patients ( $\mathrm{SA}$ group $=24$, RI group $=27$ ) who met the inclusion criteria were analyzed and subcategorized according to the size of the rotator cuff tear.

\section{Functional and Radiological Assessments}

To assess clinical and functional outcomes, shoulder specific outcome scores (Constant and American Shoulder and Elbow
Surgeons [ASES], Korean shoulder score [KSS]) were evaluated at final follow-up. Pain level was recorded using the visual analogue scale (VAS), with a score of 0 indicating no pain and 10 points indicating the worst possible pain. All scores were recorded by an independent examiner. All patients in both groups underwent MRI or ultrasonography at 6 months and 1 year after surgery to evaluate repaired tendon integrity. Most patients without symptoms of rotator cuff retear were assessed with ultrasound. Healed tendon integrity was defined as continuity with sufficient thickness of the repaired tendon and homogenous low intensity. Postoperative CHDs were measured by ultrasound at 6 months after surgery.

\section{Surgical Technique}

All surgeries were performed in the beach chair position with the patient under general anesthesia. A $30^{\circ}$ arthroscope was used during surgery. If a subscapularis tear was identified, arthroscopic repair was performed firsthand. Any articular side partial thickness tear of the subscapularis with more than 50\% depth of the tendon was repaired. The size of the tear was graded according to the classification of Lafosse et al. ${ }^{9)}$ The subscapularis tendon was repaired in the glenohumeral joint with the single-row technique. ${ }^{10)}$ Arthroscopic coracoplasty was conducted after subscapularis repair for appropriate orientation of the coracoplasty.

\section{Subacromial Approach}

In the SA approach, visualization of the coracoid tip was not
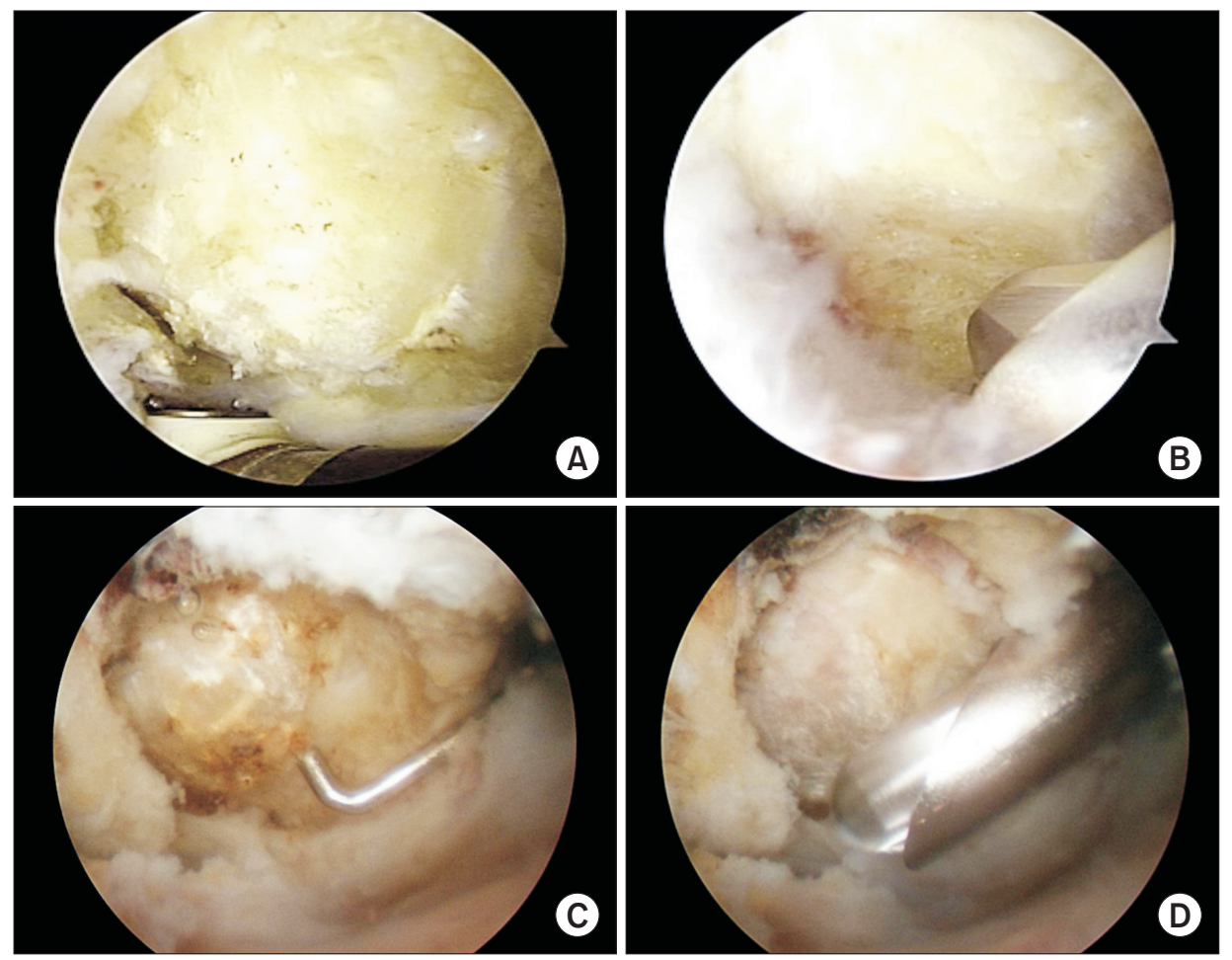

Fig. 1. Arthroscopic view of coracoid process by subacromial approach from the lateral portal (A) and coracoplasty performed by resection of the undersurface of the coracoid (B). Arthroscopic view of coracoid process by rotator interval approach from the posterior portal (C) and coracoplasty performed by resection of the posterolateral part of the coracoid tip (D). 
necessary via the posterior portal intra-articularly; thus, additional RI release was not performed. Following SA bursectomy, the lateral portal was used as the viewing portal and the anterior portal was used as the working portal. After carefully palpating the hard coracoid tip with a probe or a shaver, a radiofrequency device was used to expose the bony portion. The undersurface of the coracoid process and any existing spurs were burred down to make a flat plane. The total depth of resection of the coracoid process was $5 \mathrm{~mm}$ (Fig. 1A, B).

\section{Rotator Interval Approach}

While viewing through the posterior portal, a shaver and radiofrequency device were alternatively used to release and open the RI, which was located between the upper border of the subscapularis tendon and the long head of the biceps tendon. A probe or a shaver were used to locate the coracoid tip in the RI immediately anterior or superior or slightly inferior to the upper border of subscapularis tendon through the anterior portal. After locating the coracoid tip, a radiofrequency device was used to expose the coracoid tip. A burr was introduced through the anterior portal and the posterolateral aspect of the coracoid was resected in line with the subscapularis tendon (Fig. 1C, D).

In both approaches, additional capsular release was not performed because capsular release was not our routine procedure in coracoplasty without stiffness. In the present study, patients with severe stiffness were excluded. Following repair of the subscapularis and coracoplasty, subsequent biceps procedure, acromioplasty and supraspinatus and/or infraspinatus tendon repair were done. All rotator cuff repairs (excluding the subscapularis) were conducted using the suture bridge technique. ${ }^{11)}$

\section{Postoperative Rehabilitation}

Postoperatively, a shoulder immobilizing sling with abduction pillow was applied to each patient to maintain $30^{\circ}$ internal rotation and $20^{\circ}$ abduction. If the pain was tolerable, gentle passive forward flexion was started from the first postoperative day. Passive range of motion was restricted to $120^{\circ}$ of forward elevation and $15^{\circ}$ of external rotation for the first 6 weeks. The sling with abduction pillow was removed and full range of motion and active strengthening exercises were allowed after 6 weeks of

Table 1. Demographic and Operative Characteristics

\begin{tabular}{|c|c|c|c|}
\hline Variable & Subacromial group & Rotator interval group & $p$-value \\
\hline Number (total=51) & 24 & 27 & - \\
\hline Affected side & & & 0.83 \\
\hline Dominant & 19 & 21 & \\
\hline Non-dominant & 5 & 6 & \\
\hline Age (yr) & $67.7(45-81)$ & $66.3(40-81)$ & 0.59 \\
\hline Sex distribution & & & 0.14 \\
\hline Male & 5 & 11 & \\
\hline Female & 19 & 16 & \\
\hline Rotator cuff (supraspinatus) tear size & & & 0.24 \\
\hline No tear (isolated subscapularis tear) & $7(29.2)$ & $4(14.8)$ & \\
\hline Small & $4(16.7)$ & $5(18.5)$ & \\
\hline Medium & $5(20.8)$ & $6(22.2)$ & \\
\hline Large & $8(33.3)$ & $12(44.4)$ & \\
\hline Subscapularis tear size & & & 0.52 \\
\hline Lafosse type 1 & $13(54.2)$ & $12(44.4)$ & \\
\hline Lafosse type 2 & $9(37.5)$ & $14(51.9)$ & \\
\hline Lafosse type 3 & $2(8.3)$ & $1(3.7)$ & \\
\hline Coracohumeral distance (mm) & $8.4 \pm 2.0(4.6-14.8)$ & $8.5 \pm 2.3(3.6-13.4)$ & 0.94 \\
\hline Biceps procedure & & & 0.86 \\
\hline None & $8(33.3)$ & $11(40.7)$ & \\
\hline Tenotomy & $5(20.8)$ & $5(18.5)$ & \\
\hline Tenodesis & $11(45.8)$ & $11(40.7)$ & \\
\hline
\end{tabular}

Values are presented as number only, mean (range), number (\%), or mean \pm standard deviation (range). 
surgery. The concomitant pathologies directed the course of rehabilitation.

\section{Statistical Analysis}

Power analysis performed before the study indicated that a total sample size of 40 patients (20 patients in each cohort) would provide a statistical power of $90 \%$ with a 2 -sided $\alpha$ level of 0.05 to detect significant differences in external rotation, assuming an effect size of 1.08 (mean difference, 15; standard deviation, 13.9). This was based on the mean and standard deviation of external rotation observed in a pilot study.

PASW software ver. 18.0 for Windows (IBM Co., Armonk, NY, USA) was used for all statistical analyses. The Student t-test, Fisher's exact test, and Pearson's $\chi^{2}$ test were used to analyze potential differences between groups. A $p<0.05$ was considered significant.

\section{Results}

\section{Patient Demographics}

In the SA group $(\mathrm{n}=24)$, the mean patient age was $67.7 \pm$ 9.2 years (range, 45 to 81 years) and the mean follow-up period after surgery was $22.6 \pm 7.5$ months (range, 18 to 41 months). In the RI group $(n=27)$, the mean patient age was $66.3 \pm 9.6$ years (range, 40 to 81 years) and the mean follow-up period after surgery was $22.7 \pm 6.8$ months (range, 16 to 45 months). No significant differences were found in the demographic data between the two groups in terms of age, sex, dominant shoulder, symptom duration, or preoperative rotator cuff tear size (Table 1).

\section{Outcomes}

Clinical outcomes including VAS $(p=0.33)$, average ASES $(p=0.15)$ and KSS $(p=1.6)$ scores of the two groups significantly

Table 2. Clinical Variables of Subacromial Coracoplasty and Rotator Interval Coracoplasty Groups

\begin{tabular}{|cccc|}
\hline Variable & $\begin{array}{c}\text { Subacromial } \\
\text { group }\end{array}$ & $\begin{array}{c}\text { Rotator interval } \\
\text { group }\end{array}$ & $p$-value \\
\hline VAS & & & \\
\hline Preoperative & $7.8 \pm 1.0$ & $7.9 \pm 0.9$ & 0.81 \\
\hline Last follow-up & $1.5 \pm 1.2$ & $1.8 \pm 1.2$ & 0.33 \\
\hline ASES score & & & \\
\hline Preoperative & $40.0 \pm 7.7$ & $37.0 \pm 12.1$ & 0.19 \\
\hline Last follow-up & $82.2 \pm 10.4$ & $78.1 \pm 9.7$ & 0.15 \\
\hline KSS & & & \\
\hline Preoperative & $46.4 \pm 8.1$ & $42.5 \pm 11.7$ & 0.17 \\
\hline Last follow-up & $82.4 \pm 10.4$ & $78.7 \pm 8.4$ & 1.6 \\
\hline
\end{tabular}

Values are presented as mean \pm standard deviation.

VAS: visual analogue scale, ASES: American Shoulder and Elbow Surgeons, KSS: Korean shoulder score. improved at final follow-up compared with preoperative scores. However they were not significantly different between groups (Table 2).

In the RI group, external rotation at side $(p=0.02)$ and $90^{\circ}$ abduction $(p=0.04)$ improved significantly compared to the SA group at the time of the final follow-up. However, there was no significant difference in the improvement in active elevation $(p=0.93)$ or internal rotation $(p=0.74)$ between approaches (Table 3).

The incidence of re-tear assessed at one year after surgery did not differ significantly between two groups. Ultrasound and MRI at final follow-up detected three cases (12.5\%) of rotator cuff (supraspinatus) re-tear in the SA group and three cases (11.1\%) of re-tear in the RI group $(p=0.87)$. There was one case of subscapularis re-tear in each group $(p=0.93)$ (Table 4). Preoperative and postoperative CHD between the SA group and RI group, which were measured with MRI and ultrasound respectively, did not differ significantly between the two groups $(p>0.05$ ) (Table 5 ).

\section{Discussion}

The etiology of subscapularis tendinopathy or a tear is not well established. Coracohumeral stenosis has been proposed as one of the contributing factors, and thus brought about the

Table 3. Range of Motion

\begin{tabular}{|c|c|c|c|}
\hline Variable & $\begin{array}{l}\text { Subacromial } \\
\text { group }\end{array}$ & $\begin{array}{l}\text { Rotator interval } \\
\text { group }\end{array}$ & $p$-value \\
\hline \multicolumn{4}{|l|}{ Preoperative $\left(^{\circ}\right)$} \\
\hline Forward elevation & $155.3 \pm 25.3$ & $148.7 \pm 25.0$ & 0.48 \\
\hline External rotation at side & $33.8 \pm 24.0$ & $37.1 \pm 19.8$ & 0.41 \\
\hline External rotation at $90^{\circ}$ abduction & $47.4 \pm 12.5$ & $51.4 \pm 20.1$ & 0.31 \\
\hline Internal rotation & L1 & T12 & 0.69 \\
\hline \multicolumn{4}{|l|}{ Final follow-up $\left({ }^{\circ}\right)$} \\
\hline Forward elevation & $161.3 \pm 21.5$ & $160.7 \pm 21.6$ & 0.93 \\
\hline External rotation at side & $55.4 \pm 26.5$ & $72.2 \pm 20.7$ & $0.02^{*}$ \\
\hline External rotation at $90^{\circ}$ abduction & $60.8 \pm 22.4$ & $71.67 \pm 15.5$ & $0.04^{*}$ \\
\hline Internal rotation & T9 & T10 & 0.74 \\
\hline \multicolumn{4}{|c|}{$\begin{array}{l}\text { Values are presented as mean } \pm \text { standard deviation. } \\
{ }^{\star} p<0.05 \text { (Student's t-test). }\end{array}$} \\
\hline \multicolumn{4}{|c|}{$\begin{array}{l}\text { Table 4. Tendon Integrity on Magnetic Resonance Imaging or Ultrasonogra- } \\
\text { phy at Final Follow-up }\end{array}$} \\
\hline $\begin{array}{r}\text { Subacro } \\
\qquad(\mathrm{n}\end{array}$ & $\begin{array}{l}\text { nial group } \\
=24)\end{array}$ & $\begin{array}{l}\text { Rotator interval } \\
\text { group }(n=27)\end{array}$ & $p$-value \\
\hline $\begin{array}{l}\text { Supraspinatus \& } \\
\text { infraspinatus re-tear }\end{array}$ & 12.5) & $3(11.1)$ & 0.87 \\
\hline Subscapularis re-tear & 4.2) & $1(3.7)$ & 0.93 \\
\hline
\end{tabular}

Values are presented as number (\%). 
Table 5. Pre- and Postoperative CHD

\begin{tabular}{lccc}
\hline \multicolumn{1}{c}{ Variable } & Subacromial group & Rotator interval group & $p$-value \\
\hline Preoperative CHD measured with MRI $(\mathrm{cm})$ & $0.95 \pm 0.30$ & $0.97 \pm 0.19$ & 0.72 \\
Postoperative CHD measured with ultrasound $(\mathrm{cm})$ & $0.89 \pm 0.23$ & $0.90 \pm 0.27$ & 0.89 \\
\hline
\end{tabular}

Values are presented as mean \pm standard deviation.

CHD: coracohumeral distance, MRI: magnetic resonance imaging.

need for decompressing the coracoid in the presence of subscapularis tear or subcoracoid stenosis. ${ }^{1,8,12-14)}$ Lo and Burkhart ${ }^{6)}$ reported the correlation between narrowed coracohumeral space and partial and full thickness tears of the subscapularis by a proposed mechanism called the "roller-wringer effect," in which the coracoid process compresses the superficial portion of the upper subscapularis tendon while stretching (tensile loading) the deep portion of the tendon during internal rotation of the shoulder. Several reports have shown that both arthroscopic coracoplasty through the SA approach and RI approach yields satisfactory outcomes, although RI approach has been gaining more popularity in recent years. The authors hypothesized that there would be no difference in the clinical results between the two methods. ${ }^{1-3,8,13)}$ However, the results showed that patients who had arthroscopic coracoplasty through the RI approach had better external rotation at $0^{\circ}$ and $90^{\circ}$ abduction; therefore, our null hypothesis was rejected.

Oh et al. ${ }^{4)}$ reported that the CHD was narrowest in internal rotation and there was a significant increase in the incidence of subscapularis tears in patients with CHD in internal rotation less than $6 \mathrm{~mm}$ (dynamic CHD) measured by USG. These findings imply that static CHD in neutral position is not the only factor that should be considered when performing coracoplasty.

Karnaugh et al.") reported four patients who were successfully treated with arthroscopic coracoplsty through the SA approach. Park et al. ${ }^{3)}$ also reported 23 patients who underwent SA coracoplasty with good clinical results, especially with respect to internal rotation when compared with the untreated (no coracoplsty) group. Several reports showed that either arthroscopic or open coracoplasty yields satisfactory outcomes. ${ }^{7,8)}$

$\mathrm{RI}$ approach provides several benefits. The posterolateral aspect of the coracoid is easily located and approached, which allows direct assessment of the prominence of the coracoid process and the coracohumeral space. The posterolateral aspect of the coracoid can then be specifically resected to prevent impingement. The RI approach is easy to perform, allows appropriate orientation of the coracoplasty, and permits assessment of the adequacy of decompression when compared with the SA approach.

Our results showed clinically improved outcome with low subscapularis re-tear rate in all patients at final follow-up. There were no significant differences between the SA and RI group at the time of final follow-up. However, patients who had ar- throscopic coracoplasty through the RI approach had better external rotation at $0^{\circ}$ and $90^{\circ}$ abduction. Increased external rotation in the Rl approach was an unintended result that may have been caused by the release of RI when approaching the coracoid tip from the intra-articular view. These results suggest that when performing subscapularis repair and coracoplasty, possible inflammation and scarring at the RI might cause some limitation of motion of external rotation. As with the RI approach, the tissues around and attached to the coracoid process and the subscapularis tendon are debrided. Therefore, when using the RI approach, there are less soft tissues around the repaired subscapularis site to cause scarring. ${ }^{15)}$ Huberty et al. ${ }^{16)}$ reported that concomitant coracoplasty was one of the risk factors that was negatively correlated with postoperative stiffness after arthroscopic rotator cuff repair.

Although we measured CHD preoperatively in all cases, we performed coracoplasty in all cases with subscapularis tears, regardless of $\mathrm{CHD}$. We believe that because we do not measure the acromiohumeral distance when performing acromioplasty concomitantly with supraspinatus tear, it was unnecessary to assess the CHD before performing subcoracoid decompression. Moreover, if the need for coracoplasty is indicated with narrowed $\mathrm{CHD}$, the dynamic $\mathrm{CHD}$ may be more closely correlated with subcoracoid impingement and subscapularis tear than the more frequently measured static CHD. ${ }^{4,17)}$ Similarly, Lanz et al. ${ }^{18)}$ found that the preoperative CHD was approximately $10 \mathrm{~mm}$ in their series of large subscapularis tears. However, there were no adverse effects related to additionally performed coracoplasty in the present study.

This study has several limitations. Each subgroup included a small number of cases. Although the prevalence of tears was not significantly different between groups, the rotator cuff tear size might raise some bias. Because subscapularis tears are difficult to detect even with preoperative MRI or ultrasound, ${ }^{19,20)}$ postoperative assessment may have missed partial re-tears of subscapularis tears. Furthermore, our study was not a randomized prospective study, but rather a retrospective study in which SA was performed in the early period and RI was performed in the later period.

\section{Conclusion}

Arthroscopic coracoplasty when performed concomitantly 
with subscapularis repair showed good clinical outcomes. There was no difference between the SA and RI approach at the time of the final follow-up. However, the RI approach was much simpler and showed significant increases in external rotation when compared to the SA approach.

\section{References}

1. Karnaugh RD, Sperling JW, Warren RF. Arthroscopic treatment of coracoid impingement. Arthroscopy. 2001;17(7):784-7.

2. Lo IK, Burkhart SS. Arthroscopic coracoplasty through the rotator interval. Arthroscopy. 2003;19(6):667-71.

3. Park JY, Lhee SH, Oh KS, Kim NR, Hwang JT. Is arthroscopic coracoplasty necessary in subcoracoid impingement syndrome? Arthroscopy. 2012;28(12):1766-75.

4. Oh JH, Song BW, Choi JA, Lee GY, Kim SH, Kim DH. Measurement of coracohumeral distance in 3 shoulder positions using dynamic ultrasonography: correlation with subscapularis tear. Arthroscopy. 2016;32(8):1502-8.

5. Richards DP, Burkhart SS, Campbell SE. Relation between narrowed coracohumeral distance and subscapularis tears. Arthroscopy. 2005;21(10):1223-8.

6. Lo IK, Burkhart SS. The etiology and assessment of subscapularis tendon tears: a case for subcoracoid impingement, the roller-wringer effect, and TUFF lesions of the subscapularis. Arthroscopy. 2003;19(10):1142-50.

7. Gerber C, Terrier F, Zehnder R, Ganz R. The subcoracoid space. An anatomic study. Clin Orthop Relat Res. 1987;(215): 132-8.

8. Lo IK, Parten PM, Burkhart SS. Combined subcoracoid and subacromial impingement in association with anterosuperior rotator cuff tears: an arthroscopic approach. Arthroscopy. 2003;19(10):1068-78.

9. Lafosse L, Jost B, Reiland Y, Audebert S, Toussaint B, Gobezie R. Structural integrity and clinical outcomes after arthroscopic repair of isolated subscapularis tears. J Bone Joint Surg Am. 2007;89(6):1184-93.
10. Adams CR, Schoolfield JD, Burkhart SS. The results of arthroscopic subscapularis tendon repairs. Arthroscopy. 2008;24(12):1381-9.

11. Frank JB, ElAttrache NS, Dines JS, Blackburn A, Crues J, Tibone JE. Repair site integrity after arthroscopic transosseousequivalent suture-bridge rotator cuff repair. Am J Sports Med. 2008;36(8):1496-503.

12. Gerber C, Terrier F, Ganz R. The role of the coracoid process in the chronic impingement syndrome. J Bone Joint Surg Br. 1985;67(5):703-8.

13. Freehill MQ. Coracoid impingement: diagnosis and treatment. J Am Acad Orthop Surg. 2011;19(4):191-7.

14. MacMahon PJ, Taylor DH, Duke D, Brennan DD, O'Brien J, Eustace SJ. Contribution of full-thickness supraspinatus tendon tears to acquired subcoracoid impingement. Clin Radiol. 2007;62(6):556-63.

15. Namdari S, Green A. Range of motion limitation after rotator cuff repair. J Shoulder Elbow Surg. 2010;19(2):290-6.

16. Huberty DP, Schoolfield JD, Brady PC, Vadala AP, Arrigoni P, Burkhart SS. Incidence and treatment of postoperative stiffness following arthroscopic rotator cuff repair. Arthroscopy. 2009;25(8):880-90.

17. Jang SH, Kim SB. Ultrasound measurement of coracohumeral distance in patients with or without subcoracoid impingement. J Korean Orthop US Soc. 2014;7(1):20-7.

18. Lanz U, Fullick R, Bongiorno V, Saintmard B, Campens C, Lafosse L. Arthroscopic repair of large subscapularis tendon tears: 2- to 4-year clinical and radiographic outcomes. Arthroscopy. 2013;29(9):1471-8.

19. Tung GA, Yoo DC, Levine SM, Brody JM, Green A. Subscapularis tendon tear: primary and associated signs on MRI. J Comput Assist Tomogr. 2001;25(3):417-24.

20. Adams CR, Schoolfield JD, Burkhart SS. Accuracy of preoperative magnetic resonance imaging in predicting a subscapularis tendon tear based on arthroscopy. Arthroscopy. 2010; 26(11):1427-33. 